Grand Valley State University

ScholarWorks@GVSU

$10-1-2017$

\title{
Acculturation, Stress and Birth Outcomes in Mexican and Mexican American Women
}

Paulette A. Chaponniere

Grand Valley State University, chaponnp@gvsu.edu

Follow this and additional works at: https://scholarworks.gvsu.edu/kcon_articles

Part of the Medicine and Health Sciences Commons

\section{ScholarWorks Citation}

Chaponniere, Paulette A., "Acculturation, Stress and Birth Outcomes in Mexican and Mexican American Women" (2017). Peer Reviewed Articles. 45.

https://scholarworks.gvsu.edu/kcon_articles/45

This Article is brought to you for free and open access by the Kirkhof College of Nursing at ScholarWorks@GVSU. It has been accepted for inclusion in Peer Reviewed Articles by an authorized administrator of ScholarWorks@GVSU.

For more information, please contact scholarworks@gvsu.edu. 


\title{
Volume 6, Number I (2016)
}

\section{Acculturation, Stress and Birth Outcomes in Mexican and Mexican American Women}

\author{
Paulette A. Chaponniere, PhD, MPH, RN \\ Copyright () 2016 The Author. \\ Reprints and Permissions: www.ojccnh.org/copyrights \\ DOI: http://dx.doi.org//0.9730/ojccnh.org/v6n la4
}

Chaponniere, P. A.,(2016).Acculturation, stress and birth outcomes in Mexican and Mexican American women. Online Journal of Cultural Competence in Nursing and Healthcare, 6(I), 52-69. doi: I0.9730/ojccnh.org/v6n la4

\section{Purpose}

This study examined the relationships between stress, stress buffers, acculturation and birth outcomes of infants born to 81 Mexican and Mexican American women living in West Michigan.

\section{Method}

An interrupted times series design was used to collect data prior to labor and delivery. Neuman's Systems Model was used as the theoretical framework as it illustrates how stress impacts health outcomes. Women were recruited from local health and community agencies. Interviews were conducted in English or Spanish as desired by the subject using standardized questionnaires.

\section{Results}

Acculturation was negatively correlated with age $(r=-.378, \mathrm{p}<0.001)$ and social support $(r=-.258$, $\mathrm{p}=.02$ ). Bicultural women had the highest mean birth weight, and very Mexican-oriented women had the longest gestation. The third trimester of pregnancy was significantly different from the second trimester for stress, coping and social support. The women least integrated in either culture, e.g. marginalized (ARSMA-II), had the most stress. Spiritual coping predicted weight $(\beta$ $=.278$ ) while pregnancy distress $(\beta=-.237)$ and sense of belonging ( $\beta=-.258$ ) predicted length of gestation.

\section{Conclusion}

Pregnancy-related distress was able to penetrate all lines of defense and impacted the core per Neuman's Systems Model. Women who had strong spiritual coping and a sense of belonging were able to deflect stress and thus protect their core resulting in healthy birth outcomes. Nurses could thus promote healthier birth outcomes by focusing on social support and coping, especially with women who are culturally marginalized. These results add to the understanding of the Latino paradox.

\section{Keywords}

acculturation, Latino paradox, pregnancy-related stress, social support, coping, optimism, birth weight and gestation, Neuman's Systems Model 


\section{Introduction}

When deciding how to use limited resources, public health nurses analyze trends in health data, including morbidity and mortality. Preterm births increased more than 30\% from 1981 - 2006. Since 2006, rates have fallen. These births mainly occurred between 34 to 36 weeks of gestation (Hamilton, Martin, \& Ventura, 2012). A preterm birth costs 10 times more than a full term birth (March of Dimes, 2013, 2007). Medical care is not the only cost factor. Prematurity has a long-term impact on a child's motor and sensory development leading to an increased risk for learning difficulties and behavioral problems (Ahlsson, Kaijser, Adami, Lundgren, \& Palme, 2015).

In order to understand the risk factors associated with preterm labor and low birth weight (LBW) babies, health professionals seek to unveil underlying biomedical conditions such as diabetes. However, modifying biomedical conditions is not sufficient to reverse the current trends, as approximately $50 \%$ of preterm births have no iatrogenic cause. Because of this, nurses need to understand the psychosocial conditions which are associated with health outcomes. The purpose of this time series study was to investigate the association between stress (state, perceived and pregnancy-related stress), stress buffers (social support, coping and optimism), acculturation and birth outcomes (length of gestation and birth weight) of infants born to Mexican and Mexican-American women living in West Michigan. Neuman's stress model was used as the theoretical framework.

\section{Stress and Pregnancy}

\section{Literature Review}

Stress has both biological and psychosocial components. Biologically, it affects preterm birth through the corticotrophin-releasing hormone $(\mathrm{CRH})$. Higher levels of maternal anxiety have been found to be positively correlated with increases in $\mathrm{CRH}$, and elevated $\mathrm{CRH}$ levels at 33 weeks' gestation increased the risk for spontaneous birth (Kramer et al., 2013). The psychosocial dimension may include current stress (state), stress over a time (perceived) and pregnancy-related distress, as well as specific worries relating, for example, to the fetus or the delivery process. Stress, if not well managed or buffered, can lead to poor birth outcomes. Social support, coping and optimism have been examined as buffers to stress during pregnancy. Acculturation has emerged as another psycho-social variable which impacts health outcomes in general (Ruiz, Pickler, Marti \& Jallo, 2013).

\section{Stress Buffers and Pregnancy}

Social support has been found to impact birth outcomes across all ethnic groups. Seminal work by Collins, Dunkel-Schetter, Lobel and Scrimshaw (1993) found that women with strong social support had healthier babies. This early finding was further validated by Campos, Dunkel Shetter, Adbou, Hobel, Glynn and Sandman (2008). Among Latinas, social support during pregnancy is often provided by the maternal grandmother with additional support from the father of the baby and a network of immediate family and friends (Harley \& Eskenazi, 2006; Thornton et al., 2006). Landale, Oropesa, Ilanes and Gorman (1999) found that Puerto Rican women who lived with the baby's father throughout the pregnancy reported lower levels of stress than women who did not. This early finding continues to be pertinent. Perception of social support, in contrast to enacted support, seems to have a stronger association with the onset of preterm labor. Nylen, O'Hara and Engledinger (2013) found that women experiencing prenatal depression had poorer birth outcomes when they perceived they had less support from their partners.

An individual's culture shapes how he or she copes with stress such that one method of coping is used more than others. It may involve avoidance, active coping or spiritual coping. Avoidance can include denial, distancing, disengaging or detaching from a problem and 
escape. Active coping is problem-based and involves planning and preparation. Spiritual coping could include positive appraisal ('felt lucky to be a woman to experience pregnancy') or prayer (Yali \& Lobel, 1999). Certain cultural values such as familism may be protective and result in better birth outcomes (Abdou, Dominguez, \& Myers, 2013). Active coping may be interpreted as a form of independence and assertiveness which could clash with cultural values of familism and collectivism, and as a result, turn into a source of stress. Farley, Galves, Dickinson, and Perez (2005) found that Mexican immigrants were more likely to use positive reframing (acceptance), denial and religion as coping strategies compared to Mexican-Americans and non-Hispanic whites. Torres and Rollock (2004) indicated that there was a minimal use of active coping techniques among Hispanics, though it was strongly associated with less acculturative stress.

In addition to using coping strategies, one's spiritual health also impacts health outcomes. One area to assess is optimism or hopefulness. This is a spiritual disposition in which an individual has positive expectations for the future, expects to do well, and anticipates favorable outcomes (Lobel, Yali, Zhu, DeVincent, \& Meyer, 2002; Rini, Dunkel-Schetter, Sandman, \& Wadhwa, 1999). Optimism and hope have been referred to as uni-dimensional traits and used interchangeably by some researchers (Bryant \& Cvengros, 2004). Since the early 1990's, optimism has been shown to affect health outcomes among cancer survivors and heart attack survivors (Carver, Scheier \& Segerstrom, 2010; Kim, Smith, \& Kubzansky, 2014). It has been included more recently in pregnancy studies. Lobel, DeVincent, Kaminer, and Meyer (2000) found that Anglo women who were the least optimistic during pregnancy delivered LBW babies and also experienced high levels of stress. Some studies have examined how acculturation and depression affect health outcomes. Romero, Carvajal, Valle, and Orduña (2007), using gen- erational status as a proxy measure for acculturation, found that cultural stress was associated with more depressive symptoms and less optimism among Latino, Asian American, and European adolescents. Few researchers have examined the relationship between optimism and birth outcomes in different cultural groups.

\section{Acculturation and Pregnancy Health}

Acculturation is the process by which immigrants modify their own cultural beliefs and practices as they come in contact with another culture and gradually adopt and incorporate the characteristics of the prevailing culture (Purnell \& Paulanka, 2008, p. 352). During this process, immigrants may become marginalized both from their culture of origin and the new culture. Accordingly, adaptation to a new culture may become a source of stress. Acculturative stress occurs when an individual perceives that he/she is unable to succeed in the new cultural environment (Schwartz, Unger, Zamboanga, \& Szapocznik, 2010). This additional stress results in poorer health outcomes. According to Ham, Yore, Kruger, Health, and Moeti (2000), the "prevalence of chronic conditions (e.g., cardiovascular diseases, diabetes, hypertension and obesity) tend to increase as they [Mexican immigrants] become acculturated into U.S. society, even as their access to health care services tends to improve" (para. 1). Higher acculturation to the Anglo culture has been associated with higher prenatal stress, which has been correlated with preterm delivery (Bond et al., 2002; Jones \& Bond, 1999; Kreither, Cole, Brand, Lobele, \& Coussons-Read, 2011). Additionally, there is some evidence that acculturation positively influences the use of preventive services (Balcazar Krull \& Peterson, 2001; Lara, Gamboa, Kahramanian, Morales, \& Bautista, 2005).

Moreover, healthy birth outcomes are influenced by many variables including socio-economic status (SES), education and access to care. Poverty has consistently been linked to poor health outcomes for all racial and ethnic 
groups with the exception of Latinos (Rauh, Andrews, \& Garfinkel, 2001). This unexpected pattern has been called the Latino or Hispanic paradox. This paradox is evident during pregnancy as, first generation Latinas, despite having a lower socioeconomic status, have healthier birth outcomes compared to subsequent generations (Romero, Duke, Dabelear, Romero, Ogden, 2012; Weigers \& Sherraden, 2001).

Another possible explanation for fewer LBW or preterm births among Mexican immigrants is that women who live in areas with a high concentration of Mexican and Mexican Americans may have stronger social and cultural support, and, better access to culturally appropriate prenatal care as providers respond to this group's linguistic needs (McGlade, Saha, \& Dahlstorm, 2004). Finch and Vega (2003) found acculturative stress to have a negative influence on overall health indicators, while social support had a positive influence. More recently, D'Anna-Hernandez and Flores (2015) found that acculturative stress impacted pregnant Mexican-American women. Even though the Latino paradox usually holds true mainly for current and first-generation immigrants, it continues to occur in northern New Mexico, even for multiple generations as women have maintained their cultural patterns which foster social support for pregnant women (Domian, 2001).

In light of the literature review, there exists a gap in understanding the Latino paradox as it pertains to birth outcomes. Many questions remain unanswered such as: Does a change in coping style among Mexican and Mexican American women relate to an increased risk of preterm labor or of LBW babies? Does acculturation to Anglo culture act as a buffer or stressor? Does optimism buffer stress experienced by this aggregate? As the youngest and fastest growing minority in the USA, this lack of information is problematic considering there are 50.5 million Latinos in the USA (United States Census Bureau, Census 2010).

\section{Theoretical Framework}

Neuman's Systems Model was used as the theoretical framework for this study as it expanded Seyle's seminal work on stress and homeostasis to include factors that can buffer the impact of stress so that an individual can return to equilibrium and health (Neuman, 1995; Sitzman \& Eichelberger, 2004). The first level of defense, the flexible line, can be strengthened or weakened by factors which can change rapidly such as nutrition, sleep, or perceptions of a situation. The flexible line protects the second level of defense which is the normal state of wellness. This second level of defense includes coping patterns, culture, spiritual health, and life style factors. If stressors penetrate both levels of defense, the lines of resistance are activated (e.g., an increase in CRH or white blood cells to protect the core from harm). The response a pregnant woman has to external stressors, both at the flexible line of defense and the normal line of defense, will either be protective or detrimental and may impact her pregnancy outcome.

In this study, in addition to stressors (e.g., state, perceived and pregnancy-related stress), three stress buffers were examined (social support, coping, and optimism) as well as acculturation. Social support and perception of stress were included in the flexible line of defense due to their situational and rapidly changeable nature. Coping style, optimism and acculturation, which are usually internalized and fairly stable, were included in the normal line of defense.

\section{Purpose}

The purpose of this study was to investigate the relationship between stress (state, perceived and pregnancy-related stress), stress buffers (social support, coping and optimism), acculturation, and birth outcomes (length of gestation and birth weight) of infants born to Mexican and Mexican-American women living in West Michigan.

It was hypothesized that in pregnant Mexican and Mexican-American women: 
1. Pregnancy-related stress rather than state or perceived stress would penetrate all lines of defense resulting in poorer birth outcomes.

2. Perceived social support during pregnancy would strengthen the flexible line of defense thus resulting in better birth outcomes.

3. Optimism would strengthen the normal line of defense more than a subject's coping style.

4. Women with less acculturation to the Anglo culture would have stronger normal lines of defense (buffering variables) thus resulting in better birth outcomes.

5. There would be a negative relationship between stress indicators at Time 2 (third trimester) and buffering variables at Time 1 (first or second trimester), such that women who had higher levels of optimism, proactive coping and high perceived social support would have less perceived stress and pregnancy related-distress at Time 2 .

\section{Design}

\section{Methodology}

A prospective interrupted time series study design was chosen with no comparison group. As recall bias has been shown to occur after delivery of a premature baby (Whitehead, Hill, Brogan, \& Blackmore-Prince, 2002), it was necessary to interview women about pregnancy stress and social support before the onset of labor. Data were collected from September 2006 to January 2009. The study was approved by the institutional review boards of each health agency where individuals were recruited as well as the two academic institutions with which the researcher was affiliated.

\section{Variables}

The following potential confounders based on the literature review were included in order to determine their influence on results: age, medical conditions such as diabetes and hypertension, obstetrical history, subject's body mass index (BMI) prior to pregnancy, prenatal care, smoking and substance use history, income, education, stability of housing, and employment. The independent variables selected to measure stress were: current stress state, perceived stress (stress over the last month) and pregnancy-related stress. Social support, coping, optimism and acculturation were chosen as the independent variables for stress buffering. Two dependent variables were used: birth weight measured in ounces and gestational age measured in weeks.

\section{Questionnaires}

Standardized questionnaires in English and Spanish with well documented reliability and validity were used to collect data (Chaponniere, 2010). Women could choose to complete questionnaires in their preferred language or have the questions read to them by trained interviewers rather than fill in the forms. The instruments used in this study were the: Acculturation Rating Scale for Mexican Americans - II (ARSMA-II), State-Trait Anxiety Inventory (STAI), Perceived Stress Scale (PSS-10), Prenatal Distress Questionnaire (PDQ), Interpersonal Support Evaluation List (ISEL-12, Prenatal Coping Inventory (PCI), and, Life Orientation Test-revised (LOT-R).

As acculturation is multi-dimensional, the ARSMA-II was selected to determine acculturation status. This instrument comprises two five point subscales. The first subscale yields five levels of acculturation: very Mexican-oriented, Mexican-oriented to approximately balanced-bicultural, slightly Anglo-oriented, strongly Anglo-oriented, and Anglicized (very assimilated). The second subscale classifies the individual's level of integration: integration, assimilation, separation and marginalization. The State scale of the State-Trait Anxiety Inventory (STAI) captures the current level of tension and apprehension. The Perceived Stress Scale (PSS-10) identifies an individual's perception of stress over the last month. Yali and Lobel's 
(1999) Prenatal Distress Questionnaire (PDQ) and Prenatal Coping Inventory (PCI) were developed specifically to address aspects of pregnancy which are not included in either the STAI or the PSS-10, such as worries about the unborn child's health. Cohen and Hoberman's Interpersonal Support Evaluation List (ISEL-12, 1983) was used for perceived social support and consists of three subscales of four items each tangible (perceived availability of material aid); appraisal (perceived availability of someone to talk to about one's problems); and belonging (perceived availability of people one can do things with). The LOT-R (Life Orientation Test-revised) was used to measure optimism. The PDQ, PCI and health history questionnaires were not available in Spanish. They were first translated into Spanish by a commercial translation service and back-translated by a bilingual psychologist.

\section{Sample}

Over the last two decades, more Mexican and Mexican Americans, drawn by the employment opportunities in agriculture, have come to settle in West Michigan. They are becoming the largest minority group in Kent and Ottawa counties (where the subjects were recruited), increasing from $4 \%$ of the population (1990) to $8.6 \%$ (2010), and $2.6 \%$ to $9.7 \%$, respectively (United States Census Bureau, 2013). The Pew Hispanic Center estimated that less than 50 individuals were undocumented in 2010 (p. 15). The American Immigration Council (2015) reported that less than $1.5 \%$ of the population in Michigan was undocumented in 2012 (para. 5).

A non-probability convenience sample of 84 pregnant Latinas aged 16 to 41 was obtained. Women were self-referred, referred by friends or relatives, and agency-referred from health departments, community agencies and churches. Immigration status may have impacted self-referral, though recruitment information and consent forms specifically stated that all interviews would be anonymous and data would not be shared with government agencies. Women recruited through community agencies were already receiving government services. Women completed the questionnaires in their homes, or wherever they felt most comfortable. Base line data for all variables were obtained in the first or second trimester (Time 1). A second collection of data for stress and buffering variables was obtained during the third trimester (Time 2). During the postpartum period, data on birth outcomes were obtained by phone call or from medical records.

A total of 84 women entered the study and 54 $(66.7 \%)$ completed questionnaires twice (times 1 and 2). Birth outcomes were obtained for 81 women as 3 women were lost to follow-up. These 3 women were first generation Mexican immigrants. Their biomedical data was similar to the rest of the sample as well as their acculturation scores. First interviews were usually conducted in the second trimester of pregnancy $(54.8 \%)$, either because women were not referred earlier, or had not started prenatal care before then. Six women had their babies before the second interview could be implemented, thus giving a final sample size of 75 women to examine birth outcomes.

Women were aged 16 to 41 years, with a mean of 25 years. Marital status was equally distributed between married $(45.3 \%)$ and never married (50.7\%). Most women were receiving prenatal care $(96.4 \%)$ and were on Medicaid $(74.7 \%)$. The majority of the subjects $(78.6 \%)$ were first generation Mexican immigrants. The ARSMA-II scores indicated that 52 women $(61.3 \%)$ were very Mexican oriented (category 1), $17.3 \%$ were balanced bicultural (category 2), $11.9 \%$ were slightly Anglo (category 3), and the remaining $8.3 \%$ were strongly Anglicized (category 4). Two-thirds of the women requested to have their interviews conducted in Spanish.

The majority of the women were of the Catholic faith (64\%), and all except one had been formally educated: elementary $(20 \%)$, middle school (17.3\%), some high school (32\%), 
or a high school diploma/GED (16\%). Income level was known by two-thirds of the women $(70.6 \%)$. Given this result, the eligibility for food aid through Women, Infants and Children (WIC) was used as a proxy measure for income. In this sample, the majority of the women were receiving WIC (80\%) and Medicaid (74.7\%).

Many women identified their own mother as the person they turned to for advice about their pregnancy $(40 \%)$ followed by their husbands $(20 \%)$, mother-in-law $(8 \%)$, boyfriend $(2.6 \%)$, or other family members (40\%). Only seven women mentioned receiving advice from doctors or nurses. This was unexpected as $96.4 \%$ of the women were receiving prenatal care.

Data were analyzed using SPSS 16.0 for descriptive statistics $(N=84)$, bivariate and multivariate analyses $(n=81)$, and third trimester data $(n=75)$. For women who were interviewed twice $(n=54)$, a paired t-test was performed.

\section{Results}

Interesting patterns emerged during the analysis for all variables: health, stress, stress buffers as well as acculturation.

\section{Health History}

The women in this sample were healthy. Confounding variables-age, medical conditions such as diabetes and hypertension, obstetrical history, subject's body mass index (BMI) prior to pregnancy, prenatal care, smoking and substance use history, income, education, stability of housing, and employment-that have been correlated with an increase in poor birth outcomes in earlier studies were examined. Very few women had gestational diabetes $(8.3 \%)$, high blood pressure $(5 \%)$, or a prior vaginal infection $(26.2 \%)$. Among the women who had been pregnant before the current pregnancy, $11.6 \%$ had experienced early labor (7 of 60 ), and, $8.3 \%$ (5 of 60 ) also had bleeding, diabetes or high blood pressure. The majority of the women denied either smoking or alcohol consumption (96.4\%) and had BMI scores above $19.8 \mathrm{~kg} /$ $\mathrm{m}^{2}(85.7 \%)$.

\section{Acculturation and Demographics}

Post hoc tests revealed that there were demographic differences among the women based on their acculturation scores, whether by category or integration. Very Mexican oriented women were significantly older than the women who were slightly Anglo oriented or strongly Anglo oriented. Those with an elementary level of education had lower acculturation scores (were very Mexican oriented) compared to women with a middle school, high school or some college education. There were no significant differences in the means for income or BMI.

\section{Acculturation and Stress}

Level of integration affected stress scores. Post hoc tests showed that marginalized women (those who had difficulty accepting Mexican ideas or attitudes and were not integrated into the Anglo culture) had higher stress in all categories: current stress $(r=.344, p=.033)$, stress over the last month $(r=.288, p=.012)$, and pregnancy-related stress $(r=.264, p=.02$; Table 1$)$. There were differences among the women in how they buffered stress. Very Mexican oriented women used planning and preparation less than women who were balanced bicultural. Women who were balanced bicultural or slightly Anglo-oriented used more avoidance for coping compared to women who were very Mexican oriented. No group used spiritual coping significantly more than the other groups. Very Mexican-oriented women appraised their social support higher than strongly Anglo-oriented women and received more tangible support than slightly Anglo oriented or strongly Anglo-oriented women. No group had a stronger sense of belonging (Table 2).

\section{Birth Outcomes Acculturation and Birth Outcomes}

Even though acculturation scores were not significantly correlated with birth weight, there 
Table 1. Correlations between Acculturation Scores and Types of Stress in the Third Trimester of Pregnancy $(n=75)$

\begin{tabular}{|c|c|c|c|c|c|c|c|}
\hline & $\begin{array}{c}\text { ARSMA-II } \\
\text { scale } 1 \text { score } \\
r(p)\end{array}$ & $\begin{array}{c}\text { Anglo } \\
\text { Marginality } \\
r(p)\end{array}$ & $\begin{array}{l}\text { Mexican } \\
\text { Marginality } \\
r(p)\end{array}$ & $\begin{array}{c}\text { Mexican } \\
\text { American } \\
\text { Marginality } \\
r(p)\end{array}$ & $\begin{array}{c}\text { Current } \\
\text { stress } \\
r(\mathrm{p})\end{array}$ & $\begin{array}{c}\text { Stress over } \\
\text { last month } \\
r(p)\end{array}$ & $\begin{array}{c}\text { Pregnancy- } \\
\text { related stress } \\
r(p)\end{array}$ \\
\hline \multirow{2}{*}{ Anglo Marginality - scale 2} & $.297^{* 1}$ & & & & & & \\
\hline & $(.010)$ & & & & & & \\
\hline \multirow{2}{*}{ Mexican Marginality - scale 2} & $.360 *$ & $.504^{* *}$ & & & & & \\
\hline & $(.002)$ & $(.000)$ & & & & & \\
\hline \multirow{2}{*}{$\begin{array}{l}\text { Mexican American Marginality } \\
\text { - scale } 2\end{array}$} & .211 & $.487^{* *}$ & $.667^{* *}$ & & & & \\
\hline & $(.069)$ & $(.000)$ & $(.000)$ & & & & \\
\hline \multirow{2}{*}{ Current stress } & -.001 & -.017 & $.344^{* *}$ & .122 & & & \\
\hline & $(.991)$ & $(.883)$ & $(.003)$ & .297 & & & \\
\hline \multirow{2}{*}{ Stress over last month } & .148 & .131 & $.288^{*}$ & .153 & $.343^{\prime \prime \prime}$ & & \\
\hline & $(.206)$ & $(.264)$ & $(.012)$ & $(.190)$ & $(.003)$ & & \\
\hline \multirow{2}{*}{ Pregnancy-related stress } & .079 & .154 & $.264^{*}$ & .174 & $.415^{* *}$ & $.416^{* *}$ & \\
\hline & $(.501)$ & $(.188)$ & $(.022)$ & $(.136)$ & $(.000)$ & $(.000)$ & \\
\hline
\end{tabular}

Table 2. Correlations between Acculturation Scores and Stress Buffers in the Third Trimester of Pregnancy $(\mathbf{n}=\mathbf{7 5})$

\begin{tabular}{|c|c|c|c|c|c|c|c|c|c|c|c|}
\hline & $\begin{array}{c}\text { ARSMA-II } \\
\text { scale } 1 \\
r(p)\end{array}$ & $\begin{array}{c}\text { Anglo } \\
\text { Marginality } \\
r(p)\end{array}$ & $\begin{array}{c}\text { Mexican } \\
\text { Marginality } \\
r(p)\end{array}$ & \begin{tabular}{|c|} 
Mexican \\
American \\
Marginality \\
$r(\mathrm{p})$
\end{tabular} & $\begin{array}{c}\text { Planning/ } \\
\text { preparation } \\
r(p)\end{array}$ & $\begin{array}{c}\text { Avoidance } \\
r(p)\end{array}$ & $\begin{array}{c}\text { Spiritual } \\
\text { Coping } r(p)\end{array}$ & $\begin{array}{c}\text { Appraisal } \\
r(p)\end{array}$ & $\begin{array}{l}\text { Belonging } \\
\quad r(p)\end{array}$ & $\begin{array}{c}\text { Tangible } \\
\text { support } \\
r(p)\end{array}$ & Optimism \\
\hline \multirow{2}{*}{$\begin{array}{l}\text { Anglo Marginality - } \\
\text { scale } 2\end{array}$} & $.297^{* *}$ & & & & & & & & & & \\
\hline & $(.010)$ & & & & & & & & & & \\
\hline \multirow{2}{*}{$\begin{array}{l}\text { Mexican Marginality } \\
-2\end{array}$} & $.360^{*+}$ & $.504^{* *}$ & & & & & & & & & \\
\hline & $(.002)$ & $(.000)$ & & & & & & & & & \\
\hline \multirow{2}{*}{$\begin{array}{l}\text { Mexican American } \\
\text { Marginality - } 2\end{array}$} & .211 & $.487^{* *}$ & $.667^{* *}$ & & & & & & & & \\
\hline & $(.069)$ & $(.000)$ & $(.000)$ & & & & & & & & \\
\hline \multirow{2}{*}{$\begin{array}{l}\text { Planning and } \\
\text { preparation }\end{array}$} & .150 & .026 & .066 & -.022 & & & & & & & \\
\hline & $(.198)$ & $(.822)$ & $(.576)$ & $(.852)$ & & & & & & & \\
\hline \multirow{2}{*}{ Avoidance coping } & .159 & .097 & $.247^{*}$ & .094 & $.861^{* *}$ & & & & & & \\
\hline & $(.173)$ & $(.406)$ & $(.033)$ & $(.421)$ & $(.000)$ & & & & & & \\
\hline \multirow{2}{*}{$\begin{array}{l}\text { Spiritual \& positive } \\
\text { coping }\end{array}$} & .076 & -.018 & .011 & -.021 & $.920 *$ & $.807^{*+}$ & & & & & \\
\hline & $(.516)$ & $(.876)$ & $(.922)$ & $(.859)$ & $(.000)$ & $(.000)$ & & & & & \\
\hline \multirow{2}{*}{$\begin{array}{l}\text { Appraisal of social } \\
\text { support }\end{array}$} & $-.402^{* *}$ & -.072 & .000 & -.004 & $.277^{*}$ & $.290^{*}$ & $.315^{\star *}$ & & & & \\
\hline & $(.000)$ & $(.537)$ & $(.999)$ & $(.975)$ & $(.016)$ & $(.012)$ & $(.006)$ & & & & \\
\hline \multirow{2}{*}{ Belonging } & $-.258^{*}$ & -.051 & .075 & .116 & .203 & $.241^{*}$ & .220 & $.712^{*+}$ & & & \\
\hline & $(.025)$ & (.665) & $(.523)$ & $(.321)$ & $(.081)$ & $(.037)$ & $(.057)$ & $(.000)$ & & & \\
\hline \multirow{2}{*}{ Tangible support } & $-.337^{* *}$ & -.063 & -.057 & -.054 & .218 & $.231^{*}$ & .213 & $.660^{* *}$ & $.723^{* *}$ & & \\
\hline & $(.003)$ & $(.593)$ & $(.625)$ & $(.643)$ & $(.061)$ & $(.046)$ & $(.066)$ & $(.000)$ & $(.000)$ & & \\
\hline \multirow{2}{*}{ Optimism } & .017 & .027 & -.141 & -.059 & -.130 & $-.282^{*}$ & .010 & $-.331^{* *}$ & $-.404^{* *}$ & $-.367^{* *}$ & \\
\hline & $(.888)$ & (.818) & $(.227)$ & $(.615)$ & $(.267)$ & $(.014)$ & $(.932)$ & $(.004)$ & $(.000)$ & $(.001)$ & \\
\hline
\end{tabular}


Table 3. Birth outcomes by acculturation category $(n=81)$

\begin{tabular}{|c|c|c|c|}
\hline \multicolumn{2}{|c|}{ Acculturation category } & $\begin{array}{l}\text { Birth weight in } \\
\text { ounces }\end{array}$ & $\begin{array}{l}\text { Gestation in } \\
\text { weeks }\end{array}$ \\
\hline \multirow{3}{*}{$\begin{array}{l}\text { Very Mexican } \\
\text { Oriented }\end{array}$} & Mean & 120.6600 & 38.920 \\
\hline & $n$ & 50 & 50 \\
\hline & SD & 29.32827 & 2.4627 \\
\hline \multirow{3}{*}{$\begin{array}{l}\text { Mexican Oriented to } \\
\text { Balanced Bicultural }\end{array}$} & Mean & 126.0714 & 39.000 \\
\hline & $n$ & 14 & 14 \\
\hline & $\overline{S D}$ & 20.60793 & 1.7431 \\
\hline \multirow{3}{*}{$\begin{array}{l}\text { Slightly Anglo } \\
\text { Oriented Bicultural }\end{array}$} & Mean & 122.5000 & 39.054 \\
\hline & $n$ & 10 & 10 \\
\hline & SD & 24.73976 & 1.2553 \\
\hline \multirow{3}{*}{$\begin{array}{l}\text { Strongly Anglo } \\
\text { Oriented }\end{array}$} & Mean & 107.4286 & 38.500 \\
\hline & $n$ & 7 & \\
\hline & $\overline{S D}$ & 12.06727 & 1.1180 \\
\hline \multirow{3}{*}{ Total } & Mean & 120.6790 & 38.914 \\
\hline & $n$ & 81 & 81 \\
\hline & SD & 26.39120 & 2.1209 \\
\hline
\end{tabular}

did seem to be a pattern in the distribution. The birth outcomes for the original sample of 81 women were used for this analysis. Women who were Balanced Bicultural (ARSMA-II, scale 1) had higher birth weights. Women who were more Mexican-oriented had longer gestations than women in the other categories (Table 3).

\section{Health History and Birth Outcomes}

Prior early labor was not correlated with current length of gestation. There was a negative correlation between current diabetes and birth weight $(r=-.310, p=.01$; Chaponniere, 2010, $\mathrm{p}$. $163)$. In the stepwise regression, current diabetes $(\beta=-.518, p<.0001)$ and mother's age $(\beta=$ $.227, p=.05)$ were significant predictors of birth weight (Table 4).

\section{Stress and Birth Outcomes}

There were no significant correlations between current stress or perceived stress and birth outcomes. Length of gestation was negatively correlated with pregnancy distress $(r$ $=-.245, p=0.05$; Chaponniere, 2010, p. 156). In the stepwise regression, pregnancy distress emerged as a significant predictor of length of gestation $(\beta=-.237, p=.047$; Table 5$)$.

For the women interviewed twice $(n=54)$, a paired samples t-test was used to compare whether there was a significant difference between what women reported in the first versus the second interview. The third trimester of pregnancy was significantly different from the second trimester for pregnancy-related stress indicating that women were more worried about their pregnancy $(t(51)=-3.20, p=.002)$.

\section{Stress Buffers and Birth Outcomes}

Birth weight was positively correlated with one subcategory of coping - spiritual/positive coping style $(r=.262, p=0.02$; Chaponniere, 2010, p. 155). No significant correlations were seen between optimism and birth outcomes. In the stepwise regression, one subscale of social support, a sense of belonging, was a significant predictor of length of gestation $(\beta=.258, p=$ .039; Table 5).

Women used planning and preparation $(t$ $(53)=-2.72 ; p=.009)$ more often as a coping strategy during the last trimester. Social support for all subcategories decreased from the second to the third trimester: appraisal of social 
Table 4. Stepwise Regression for Predicting Birth Weight (n = 75)

\begin{tabular}{|c|c|c|c|c|c|c|c|c|}
\hline \multirow{2}{*}{\multicolumn{2}{|c|}{ Model }} & \multirow{2}{*}{$\mathrm{B}$} & \multirow{2}{*}{ Std. Error } & \multirow[b]{2}{*}{ Beta } & \multirow{2}{*}{$\mathrm{t}$} & \multirow{2}{*}{ Sig. } & \multicolumn{2}{|c|}{ Collinearity Statistics } \\
\hline & & & & & & & Tolerance & VIF \\
\hline \multirow[t]{2}{*}{ Step 1} & Constant & 99.072 & 12.588 & & 7.870 & .000 & & \\
\hline & Subject's age & .970 & .486 & .227 & 1.995 & .050 & 1.000 & 1.000 \\
\hline \multirow[t]{6}{*}{ Step 2} & Constant & 102.304 & 14.754 & & 6.934 & .000 & & \\
\hline & Subject's age & 1.017 & .551 & 238 & 1.846 & .069 & .821 & 1.218 \\
\hline & ARSMA-II scale 1 score & .361 & 2.071 & .024 & .174 & .862 & .703 & 1.422 \\
\hline & Anglo Marginality - scale 2 & -.066 & .667 & -.014 & -.098 & .922 & .687 & 1.456 \\
\hline & Mexican Marginality - scale 2 & -.259 & .835 & -.053 & -.310 & .757 & .477 & 2.096 \\
\hline & $\begin{array}{l}\text { Mexican American Marginality - scale } \\
2\end{array}$ & -.033 & .917 & -.006 & -.036 & .971 & .519 & 1.928 \\
\hline \multirow[t]{7}{*}{ Step 3} & Constant & 93.479 & 14.697 & & 6.361 & .000 & & \\
\hline & Subject's age & 1.057 & .533 & .248 & 1.985 & .051 & .820 & 1.220 \\
\hline & ARSMA-II scale 1 score & .065 & 2.004 & .004 & .033 & .974 & .701 & 1.427 \\
\hline & Anglo Marginality - scale 2 & -.017 & .645 & -.004 & -.026 & .979 & .686 & 1.457 \\
\hline & Mexican Marginality - scale 2 & -.297 & .807 & -.060 & -.368 & .714 & .477 & 2.096 \\
\hline & $\begin{array}{l}\text { Mexican American Marginality - scale } \\
2\end{array}$ & .019 & .886 & .003 & .021 & .983 & .518 & 1.929 \\
\hline & Spiritual \& positive & 1.072 & .438 & .278 & 2.447 & .017 & .991 & 1.009 \\
\hline \multicolumn{4}{|c|}{ a. Dependent Variable: Birth weight in ounces } & & & & & \\
\hline
\end{tabular}

Note. $\mathrm{R} 2=.052$ for Step $1(p=.05) ; \Delta R 2=.004$ for Step $2 ; \Delta R 2=.076$ for Step $3(p=.017)$.

Table 5. Stepwise Regression Analysis for Predicting Length of Gestation (n = 75)

\begin{tabular}{|c|c|c|c|c|c|c|c|c|}
\hline \multirow{2}{*}{\multicolumn{2}{|c|}{ Model }} & \multirow[b]{2}{*}{ B } & \multirow[b]{2}{*}{ Std. Error } & \multirow[b]{2}{*}{ Beta } & \multirow{2}{*}{$\mathrm{t}$} & \multirow{2}{*}{ Sig. } & \multicolumn{2}{|c|}{ Collinearity Statistics } \\
\hline & & & & & & & \multirow[t]{2}{*}{\begin{tabular}{|l|} 
Tolerance \\
\end{tabular}} & \multirow[t]{2}{*}{ VIF } \\
\hline \multirow[t]{2}{*}{ Step 1} & (Constant) & 38.715 & .786 & & 49.226 & .000 & & \\
\hline & Subject's age & .019 & .030 & .074 & .631 & .530 & 1.000 & 1.000 \\
\hline \multirow[t]{6}{*}{ Step 2} & (Constant) & 39.317 & .885 & & 44.435 & .000 & & \\
\hline & Subject's age & .011 & .033 & .042 & .329 & .743 & .821 & 1.218 \\
\hline & ARSMA-II scale 1 score & -.049 & .124 & -.054 & -.396 & .693 & .703 & 1.422 \\
\hline & Anglo Marginality - scale 2 & -.008 & .040 & -.028 & -.200 & .842 & .687 & 1.456 \\
\hline & Mexican Marginality - scale 2 & -.104 & .050 & -.346 & -2.075 & .042 & .477 & 2.096 \\
\hline & Mexican American Marginality & .080 & .055 & .231 & 1.449 & .152 & .519 & 1.928 \\
\hline \multirow[t]{7}{*}{ Step 3} & (Constant) & 39.711 & .887 & & 44.769 & .000 & & \\
\hline & Subject's age & .009 & .032 & .034 & .274 & .785 & .820 & 1.220 \\
\hline & ARSMA-II scale 1 score & -.057 & .122 & -.063 & -.471 & .639 & .702 & 1.424 \\
\hline & Anglo Marginality - scale 2 & -.006 & .039 & -.019 & -.142 & .888 & .686 & 1.457 \\
\hline & Mexican Marginality - scale 2 & -.085 & .050 & -.282 & -1.702 & .093 & .460 & 2.173 \\
\hline & Mexican American Marginality & .079 & .054 & .229 & 1.465 & .148 & .519 & 1.928 \\
\hline & Pregnancy-related stress & -1.055 & .520 & -.237 & -2.027 & .047 & .929 & 1.077 \\
\hline \multirow[t]{8}{*}{ Step 4} & (Constant) & 39.101 & .912 & & 42.857 & .000 & & \\
\hline & Subject's age & .007 & .032 & .028 & .228 & .820 & .819 & 1.220 \\
\hline & ARSMA-II scale 1 score & .011 & .123 & .012 & .090 & .929 & .654 & 1.530 \\
\hline & Anglo Marginality - scale 2 & .002 & .038 & .008 & .064 & .949 & .680 & 1.472 \\
\hline & Mexican Marginality - scale 2 & -.090 & .049 & -.300 & -1.850 & .069 & .459 & 2.178 \\
\hline & Mexican American Marginality & .067 & .053 & .195 & 1.272 & .208 & .513 & 1.949 \\
\hline & Pregnancy-related stress & -1.398 & .533 & -.314 & -2.622 & .011 & .842 & 1.187 \\
\hline & Belonging & .130 & .062 & .258 & 2.109 & .039 & .806 & 1.241 \\
\hline
\end{tabular}

Note. $\mathrm{R} 2=.005$ for Step $1(\mathrm{p}>.05) ; \Delta \mathrm{R} 2=.082$ for Step $2-$ Mexican Marginality $(\mathrm{p}<.05) ; \Delta \mathrm{R} 2=.052$ for Step 3 - pregnancy-related stress $(\mathrm{p}<.05) ; \Delta \mathrm{R} 2=.052$ for Step $4-$ pregnancy-related stress and belonging $(\mathrm{p}<.05)$. 
support $(t(53)=4.92 ; p<.001)$, belonging $(t(53)=$ $2.51 ; p=.015)$, and tangible support $(t(53)=3.52$; $p=.001$; Chaponniere, 2010, p. 185).

\section{Discussion}

The present study was conducted to investigate the relationship between stress, stress buffers, acculturation and birth outcomes in a group of Mexican and Mexican-American pregnant women. Based on Neuman's Systems Model, three core variables predicted birth outcomes: (a) birth weight was predicted by current diabetes $(\beta=-.518, p<.0001)$ and mother's age $(\beta=.227, p=.05)$, and $(b)$ length of gestation was predicted by prior early labor $(\beta=1.459, p$ $=.013$ ). These results are similar to other studies. Rosenberg, Garbers, Lipkind and Chiasson (2005), and, James-Todd et al (2014) found that chronic and gestational diabetes were significant risks for preterm births. Maternal age remains a risk factor as women older than 35 have more preterm births (Yang, Greenland, \& Flanders, 2006; Fuchs, Monet, Audibert, \& Chaillet, 2014). Prior preterm births increase the risk for subsequent preterm deliveries, and depending on the population, could vary between 1.5 to 4 -fold (Iams \& Berghella, 2010, p. 91) A maternal BMI score above $19.8 \mathrm{~kg} / \mathrm{m} 2$ is protective (Iams \& Berghella, 2010, p. 91).

Other confounders were examined. Socio-economic status (SES) has been shown to be a key variable in health status among most population groups. Neither income nor educational level had significant correlations with birth outcomes. This finding is consistent with other studies of Latinas as SES has not been shown to predict an increase in risk for LBW babies among Latinas. Religious affiliation seemed to be important as women who identified with $\mathrm{Ca}$ tholicism had babies with higher birth weights. This finding is similar to other studies (Finch \& Vega, 2003) and may indicate another source of social support.

Hypothesis one: Pregnancy-related stress rather than state or perceived stress would penetrate all lines of defense resulting in poorer birth outcomes. In this study, pregnancy-related stress was able to penetrate both the flexible and normal lines of defense as well as the lines of resistance and affect the length of gestation. This type of stress was not only correlated with length of gestation but also predicted it. Women with higher distress scores had lower gestations (Table 5). Given the physiological aspect of stress, this finding supported prior results even though $\mathrm{CRH}$ levels were not measured in this study. Higher levels of maternal anxiety have been found to be positively correlated with increases in CRH and elevated CRH levels at 33 weeks' gestation increased the risk for spontaneous birth (Kramer et al., 2013). Current stress and perceived stress did not have the same effect. This hypothesis was supported by the results.

Hypothesis two: Perceived social support during pregnancy would strengthen the flexible line of defense thus resulting in better birth outcomes. One aspect of social support affected birth outcomes. A sense of belonging, part of the flexible line of defense, was protective in that it predicted length of gestation, while tangible social support and appraisal of support did not. It is possible that, as the other two categories of social support (appraisal and tangible) were strongly correlated with sense of belonging, the main effect of this subcategory was masked in the bivariate analysis. This is a new finding as it pertains to birth outcomes. Other studies have indicated that social support was a significant variable, but these studies measured other aspects such as marital status and levels of social interaction (Dejin-Karlsson et al., 2000; Stinson et al., 2000; Vatten \& Skjaerven, 2003). This hypothesis was supported by the results.

Hypothesis three: Optimism would strengthen the normal line of defense more than a subject's coping style. Optimism did not strengthen the normal line of defense more than coping style. The normal line of defense was strengthened by spiritual/positive coping but not by planning or avoidance coping. Spiritual coping was pos- 
itively correlated with length of gestation and also predicted birth weight (Table 5). This is a new and very exciting finding which adds to research indicating the links between spiritual health and overall health (Cotton et al., 2012; Koenig, 2012; Moxey, McEvoy, Bowe \& Attia, 2011). Yali and Lobel (1999) looked at the associations between stress and coping, but had not examined the impact of coping on birth outcomes. They found that avoidance had the strongest association with pregnancy-specific distress and that "prayer was the most frequently employed strategy for coping with distress during pregnancy" (p. 46). They also noted that young women were more likely than older women to prepare, pray, and use self-care. As a large percentage of the women were either Mexican oriented or balanced bicultural in this study, it would seem plausible that they still maintained their religious practices. Spiritual coping would be valued as a strategy to manage their pregnancy (Table 2).

There was no relationship between optimism and birth outcomes. Bryant and Cvengros (2004) suggested that the "choice between distinguishing or merging hope and optimism may well depend on whether the researcher seeks to maximize predictive accuracy or simply to summarize individuals' future orientation...that optimism has stronger implications for dispositional cognitive appraisals of personal outcomes, whereas hope is more strongly tied to dispositional beliefs about capabilities" (p. 285). Optimism was selected for this study as women were anticipating an outcome. This decision was also based on prior results that optimism predicted birth weight (Lobel et al., 2000). Resilience, which includes an aspect of hope through aspiration for a better life and opportunities for education of one's children, may have been more appropriate when working with immigrant populations (Bender and Castro, 2000). This hypothesis was not supported by the results as spiritual coping was more significant than optimism.
Hypothesis four: Women with less acculturation to the Anglo culture would have stronger normal lines of defense (buffering variables) thus resulting in better birth outcomes. Birth weight and length of gestation decreased as acculturation scores increased, but this was not statistically significant. Women who were Mexican oriented to balanced bicultural carried their babies longer than any of the women in the other categories $(M=39.000, S D 1.7431)$ and had higher birth weights $(M=126.0714, S D$ 20.60793; Table 3). Acculturation appears to impact stress as well as stress buffers. Women who were in the Mexican Marginality category - women who did not identify with the Mexican culture and had not become integrated into the Anglo culture (Cuellar, Arnold and Maldonado, 1995) - had significantly more stress for all stress categories: current stress, perceived stress (over last month) and pregnancy-related stress (Table 1). These findings are similar to Zambrana, Scrimshaw, Collins, and Dunkel-Schetter (1997) who found that greater acculturation (measured with the ARSMA-I) was associated with higher prenatal stress and an increase in substance use and lower levels of social support, especially from the baby's father. Campos, Dunkel-Schetter, Walsh, and Schenker (2007) found that Mexican orientation was associated with less perceived stress, and Anglo orientation was associated with specific aspects of stress. Mexican orientation was positively associated with pregnancy anxiety while Anglo orientation was positively associated with concern about the baby's growth. Campos et al. (2011) in another study also found that "greater social support was associated with higher infant birth weights for foreign-born Latinas only" (p. 159). Women who were bicultural had higher birth weights than any other group, though it was not a significant finding (Table 3).

Acculturation also influenced stress buffers and was negatively correlated with each sub-category of social support: appraisal, sense of belonging, and tangible support. Women who 
were the least acculturated had the most social support. Bivariate analysis did not indicate significant correlations. Stepwise regression indicated that $19.3 \%$ of the variability in length of gestation could be accounted for by the sense of belonging (Table 5). This is dissimilar to Harley and Eskenazi (2006) who examined the effect of social support and health behaviors during pregnancy among 568 women of Mexican descent and found that "social support was lowest among recent Mexican immigrants and highest among women who had lived their entire lives in the United States" (p. 3055). This current finding may be due to the social context in which the subjects live. As there are growing Mexican and Mexican American communities in this region, the women who participated in this study may have maintained their traditional social support which could be lacking in communities where there are less Mexicans and Mexican Americans. It was hypothesized that acculturation would not affect coping. However, acculturation was significantly correlated with the use of planning/preparation and avoidance as coping mechanisms. Women who were marginalized used avoidance significantly more often as a coping mechanism. Marginalization may also indicate acculturative stress (Romero et al., 2007).

Hypothesis five: There would be a negative relationship between stress indicators at Time 2 (third trimester) and buffering variables at Time 1 (first or second trimester), such that women who had higher levels of optimism, proactive coping and high perceived social support would have less perceived stress and pregnancy related-distress at Time 2. Stress and stress buffers had the most impact on birth weight and length of gestation during the third trimester of pregnancy. The third trimester of pregnancy was significantly different from the second trimester for pregnancy-related stress $(t$ $(51)=-3.20, p=.002$ ) as women were more worried about their pregnancy; they used planning and preparation $(t(53)=-2.72 ; p=.009)$ to cope. Social support for all subcategories decreased: appraisal of social support $(t(53)=4.92 ; p<.001)$, belonging $(t(53)=2.51 ; p=.015)$, and tangible support $(t(53)=3.52 ; p=.001)$. Pregnancy-related stress was able to penetrate both the flexible and normal lines of defense as well as the lines of resistance and affect the length of gestation. This type of stress was not only correlated with length of gestation, but also predicted it. Women with higher pregnancy distress scores had lower gestations. Current stress and perceived stress did not have the same effect. (Table 5). Given the physiological aspect of stress, this result supports prior results even though CRH levels were not measured in this study (Kramer et al., 2013).

Although specific interventions were not included in this study, results could be beneficial in helping nurses identify strategies to enhance maternal coping skills and social support which are shown to be protective of the unborn child.

\section{Conclusion}

The purpose of this study was to investigate the association between stress, stress buffers, acculturation and birth outcomes of infants born to Mexican and Mexican-American women living in West Michigan. Acculturation did not significantly impact birth outcomes but was correlated with stress and stress buffers. Women who were marginalized (had difficulty accepting Mexican ideas and attitudes) had higher stress in all categories: current stress, stress over the last month and pregnancy-related stress. Very Mexican oriented women used planning and preparation less than women who were balanced bicultural. Women who were balanced bicultural or slightly Anglo-oriented used avoidance for coping more than women who were very Mexican oriented. No group used spiritual coping significantly more than the other groups. Very Mexican-oriented women appraised their social support higher than strongly Anglo-oriented women and received more tangible support than slightly Anglo oriented or strongly Anglo-oriented women. No 
group had a stronger sense of belonging. These results further the understanding of the Latino paradox and how the acculturation process and stress buffers affect birth outcomes.

Several new findings emerged through this study. Based on Neuman's System Model of how stress affects health outcomes, pregnancy distress emerged as a significant predictor of length of gestation. It was able to penetrate both the flexible and normal lines of defense, and, affect the core. The normal line of defense was strengthened by certain components of coping and social support. Birth weight was positively correlated with spiritual/positive coping and a sense of belonging was a significant predictor of length of gestation. The third trimester of pregnancy was significantly different from the second trimester. Women were more worried about their pregnancy (pregnancy-related distress) and used planning and preparation more as a coping strategy during the third trimester. Social support for all subcategories decreased in the third trimester: appraisal of social support, sense of belonging and tangible support.

As this study used a convenience sample, results cannot be generalized to all immigrant women, in particular Mexican women. Undocumented immigrants may not have come forward due to Immigration and Naturalization Service deportation policies. Resilience may have been more appropriate to use in this study instead of optimism. In addition, acculturative stress was not included in the stress variables and may have also impacted the results. Thus a new question emerges to determine how acculturative stress impacts birth outcomes versus pregnancy-related stress.

Further studies with a larger and more diverse sample are needed. The instruments designed for Mexicans and Mexican Americans will need to be modified before use with other Latina groups. These modifications are especially critical as not all Latinas speak Spanish, and, even among those who do, there are nuances in language use that may affect results. Because acculturation impacts both social support and coping, it is vital that nurses quickly identify the sense of marginality and pregnancy-related stress in order to plan interventions for pregnant Mexican and Mexican American women especially during the third trimester. 


\section{References}

Abdou, C. M., Dominguez, T. P., \& Myers, H. F. (2013). Maternal familism predicts birth weight and asthma symptoms three years later. Social Science \& Medicine, 76, 29-38. Retrieved from http://dx.doi.org/10.1016/j. socscimed.2012.07.041

Ahlsson, F., Kaijser, M., Adami, J., Lundgren, M., \& Palme, M. (2015). School performance after preterm birth. Epidemiology, 26(1), 106-111. doi: 10.1097/ EDE.0000000000000171

American Immigration Council (2015). New Americans in Michigan. Retrieved from http://www.immigrationpolicy.org/just-facts/new-americans-michigan

Balcazar, H., Krull, J. L., \& Peterson, G. (2001). Acculturation and family functioning are related to health risks among pregnant Mexican American women. Behavioral Medicine, 27(2), 62-71. Retrieved from http://proquest.com

Bender, D. E., \& Castro, D. (2000). Explaining the birth weight paradox: Latina immigrants' perceptions of resilience and risk. Journal of Immigrant Health, 2(3), 155-173. Retrieved from http://proquest.com

Bond, M. L., Jones, M. E., Cason, C., Campbell, P., \& Hall, J. (2002). Acculturation effects on health promoting lifestyle behaviors among Hispanic origin pregnant women. Journal of Multicultural Nursing and Health, $8(2), 61-69$.

Bryant, F. B., \& Cvengros, J. A. (2004). Distinguishing hope and optimism: Two sides of a coin or two separate coins? Journal of Social and Clinical Psychology, 23(2), 273-302.

Campos, B., Dunkel-Schetter, C., Walsh, J. A., \& Schenker, M. (2007). Sharpening the focus on acculturative change: ARSMA-II, stress, pregnancy anxiety, and infant birth weight in recently immigrated Latinas. Hispanic Journal of Behavioral Sciences, 29, 209-224. doi: 10.1177/0739986307300841

Campos, B., Dunkel-Schetter, C., Abdou, C. M., Hobel C. J., Glynn, L. M., \& Sandman C. A. (2008). Familism, social support, and stress: Positive implications for pregnant Latinas. Cultural Diversity and Ethnic Minority Psychology, 14(2), 155-162. Doi:10.1037/10999809.14.155

Carver, C. S., Scheier, M. F., \& Segerstrom, S. C. (2010) Optimism. Clinical Psychology Review, 30, 879-889. doi:10.1016/j.cpr.2010.01.006

Chaponniere, P. (2010) Acculturation, pregnancy-related stress and birth outcomes in Mexican and Mexican-American women (Doctoral dissertation). Retrieved from ProQuest. (AAI3405768)
Cohen, S., \& Hoberman, H. (1983). Positive events and social supports as buffers of life change stress. Journal of Applied Social Psychology, 13, 99-125. Retrieved from http://www.psy.cmu.edu/ scohen/ISELscore.html

Collins, N. L., Dunkel-Schetter, C., Lobel, M., \& Scrimshaw, S. C. M. (1993). Social support in pregnancy: Psychosocial correlates of birth outcomes and postpartum depression. Journal of Personality and Social Psychology, 65(6), 1243-1258. Retrieved from http:// dx.doi.org/10.1037/0022-3514.65.6.1243

Cotton, S., Weekes, J. C., McGrady, M. E., Rosenthoal, S. L., Yi, M. S., . . Tsevat, J. (2012). Spirituality and religiosity in urban adolescents with asthma. Journal of Religion and Health, 51, 118-131. doi: 10.1007/s10943010-9408-x

Cuellar, I., Arnold, B., \& Maldonado, R. (1995) Acculturation rating scale for Mexican Americans-II: A revision of the original ARSMA scale. Hispanic Journal of Behavioral Sciences, 17(3), 275-304. doi: 10.1177/07399863950173001

D'Anna-Hernandez, L., \& Flores, A-M. B. A. (2015) Acculturative stress negatively impacts maternal depressive symptoms in Mexican-American women during pregnancy. Journal of Affective Disorders, 176, 35-42. doi:10.1016/j.jad.2015.01.036

Dejin-Karlsson, E., Hanson, B. S., Ostergren, P-O., Lindren, A., Sjoberge, N-O., \& Marsal, K. (2000). Association of a lack of psychological resources and the risk of giving birth to small for gestational age infants: A stress hypothesis. BJOG: An International Journal of Obstetrics \& Gynaecology, 107(1), 89-100. doi: 10.1111/ j.1471-0528.2000.tb11584.x

Domian, E. W. (2001). Cultural practices and social support of pregnant women in a Northern Mexican community. Journal of Nursing Scholarship, 33(4), 331-336. doi: 10.1111/j.1547-5069.2001.00331.x

Farley, T., Galves, A., Dickinson, L. M., \& Perez, M. J. D. (2005). Stress, coping, and health: A comparison of Mexican immigrants, Mexican-Americans, and non-Hispanic whites. Journal of Immigrant Health, 7(3), 213-220. doi: 10.1007/s10903-005-3678-5

Finch, B. K., \& Vega, W. A. (2003). Acculturation stress, social support, and self-rated health among Latinos in California. Journal of Immigrant Health, 5(3), 109117. Retrieved from http://proquest.com

Fuchs, F., Monet, B., Audibert, F., \& Chaillet, N. (2014) Impact of advanced maternal age on preterm birth. American Journal of Obstetrics \& Gynecology, supplement. doi: 10.1016/j.ajog.2013.10.814

Ham, S. A., Yore, M. M., Kruger, J., Health, G. W., \& Moeti, R. (2007). Physical activity patterns among Latinos in the United States: Putting the pieces together. Preventing Chronic Disease, 4(4), 1-13: A92.

Hamilton, B. E., Martin, J. A., Ventura, S. J. (2012) Births: 
Preliminary data for 2011. National Vital Statistics Reports, 61(5). Hyattsville, MD: National Center for Health Statistics.

Harley, K., \& Eskenazi, B. (2006) Time in the United States, social support and health behaviors during pregnancy among women of Mexican descent. Social Science \& Medicine, 62, 3048-3061. doi:10.1016/j. socscimed.2005.11.036

Iams, J. D., Berghella, V. (2010) Care for women with prior preterm birth. American Journal of Obstetrics \& Gynecology, 203, 89-100. doi: 10.1016/j.ajog.2010.02.004

James-Todd, T., Wise, L., Boggs, D., Rich-Edwards, J., Rosenberg, L., \& Palmer, J. (2014) Preterm birth and subsequent risk of type 2 diabetes in black Women. Epidemiology, 25(6), 805-810. doi:10.1097/ EDE.0000000000000167

Jones, M. E., \& Bond, M. L. (1999). Predictors of birth outcome among Hispanic immigrant women. Journal of Nursing Care Quality, 14(1), 56-62. doi:10.1097/00001786-199910000-00007

Kim, E., S., Smith, J., \& Kubzansky, L. D. (2014) Prospective study of the association between dispositional optimism and incident heart failure. Circulation: Heart Failure, 7, 385-387. doi:10.1161/CIRCHEARTFAILURE.113.000644

Koenig, H. G. (2012) Religion, spirituality, and health: Research and clinical implications. International Scholarly Research Network, 2012. 33 pages. doi:10.5402/2012/278730

Kramer, M. S., Lydon, J., Goulet, L., Kahn, S., Dahlou, M., Platt, R. W., Sahram, S., Meaney, M. J., \& Séguin, L. (2013) Maternal stress/distress, hormonal pathways and spontaneous preterm birth. Pediatric and Perinatal Epidemiology, 27, 237-246. doi: 10.1111/ppe.12042

Kreither, M. O., Cole, S., Brand, C., Lobel, M., \& Coussons-Read, M. E. (2011) Higher acculturation is related to low social support, elevated stress and negative feelings, and increased in poor pregnancy outcomes in Latinas. Brain, Behavior, and Immunity (25), S179-S242. doi:10.1016/j.bbi.2011.07.131

Laganá, K. (2003). Come bien, camina y no se preocupe-eat right, walk, and do not worry: Selective biculturalism during pregnancy in a Mexican American community. Journal of Transcultural Nursing, 14(2), 117-124. doi: $10.1177 / 1043659602250629$

Landale, N. S., Oropesa, R. S., Ilanes, D., \& Gorman, B. K. (1999). Does Americanization have adverse effects on health? Stress, health habits and infant health outcomes among Puerto Ricans. Social Forces, 78(2), 613642. doi: $10.2307 / 3005569$
Lara, M., Gamboa, C., Kahramanian, M. I., Morales, L. S. \& Bautista, D. E. H. (2005). Acculturation and Latino health in the United States: A review of the literature and its sociopolitical context. Annual Review of Public Health, 26, 367-397._doi:10.11456/annurev. publhealth.26.021304.144615

Lobel, M., DeVincent, C. J., Kaminer, A., \& Meyer B. A. (2000). The impact of prenatal maternal stress and optimistic disposition on birth outcomes in medically high-risk women. Health Psychology, 19(6), 544-553. doi:10.103W0278-6I33.19.6.544

Lobel, M., Yali, A. M., Zhu, W., DeVincent, C. J., \& Meyer, B. A. (2002). Beneficial associations between optimistic dispositions on emotional distress in highrisk pregnancy. Psychology and Health, 17(1), 77-95. doi:10.1080/08870440290001548

March of Dimes $(2013,2007)$. Prematurity campaign. Retrieved from http://www.marchofdimes.com/mission/prematurity-campaign.aspx

McGlade, M. S., Saha, S., \& Dahlstrom, M. E. (2004). The Latina paradox: An opportunity for restructuring prenatal care delivery. American Journal of Public Health, 94(12), 2062-2066. Retrieved from http://www.ncbi. nlm.nih.gov/pmc/articles/PMC1448590/pdf/0942062. pdf

Moxey, A., McEvoy. M., Bowe, S., \& Attia., J. (2011). Spirituality, religion, social support and health among older Australian adults. Australasian Journal on Ageing, 30(2), 82-22. doi: 10.1111/j.1741-6612.2010.00453

Neuman, B. (1995). The Neuman Systems Model ( $3^{\text {rd }}$ ed.). Norwalk, Conn: Appleton \& Lange.

Nylen, K. J., O'Hara, M. W., \& Engledinger, J. (2013) Perceived social support interacts with prenatal depression to predict birth outcomes. Journal of Behavioral Medicine, 36, 427-440. doi: 10.1007/s10865-012-9436-y

Pew Hispanic Center (2011). Unauthorized immigrant population: National and state trends, 2010. Washington, D.C.: Pew Research Center. Retrieved from http:// www.pewhispanic.org/files/reports/133.pdf

Purnell, L. D., \& Paulanka, B. J. (2008). Transcultural health care: A culturally competent approach ( $3^{\text {rd }}$ ed.). Philadelphia, PA: F. A. Davis Company.

Rauh, V. A., Andrews, H. F., \& Garfinkel, R. S. (2001). The contribution of maternal age to racial disparities in birth weight: A multilevel perspective. American Journal of Public Health, 91(11), 1815-1825. Retrieved from http://www.ncbi.nlm.nih.gov/pmc/articles/ PMC1446885/

Rini, C. K., Dunkel-Schetter, C., Wadhwa, P. D., \& Sandman, C. A. (1999). Psychological adaptation and birth outcomes: The role of personal resources, stress and socio-cultural context in pregnancy. Health Psychology, 18(4), 333-345. Retrieved from http://proquest.com 
Romero, C. X., Duke, J. K., Dabelear, D., Romero, T. E., Ogden, L. G. (2012) Does the epidemiologic paradox hold in the presence of risk factors for low birth weight infants among Mexican-born women in Colorado? Journal of Health Care for the Poor and Underserved, 23(2), 604-614. Retrieved from ProQuest Medical Library

Romero, A. J., Carvajal, S. C., Valle, F., Orduña, M. (2007). Adolescent bicultural stress and its impact on mental well-being among Latinos, Asian Americans, and European Americans. Journal of Community Psychology, 35(4), 519-534. doi: 10.1002/jcop.20162

Rosenberg, T. J., Garbers, S., Lipkind, H., \& Chiasson, M. A. (2005). Maternal obesity and diabetes as risk factors for adverse pregnancy outcomes: Differences among 4 racial/ethnic Groups. American Journal of Public Health, 95(9), 1545-1551. doi: 10.2105/ AJPH.2005.065680

Ruiz, R. J., Pickler, R. H., Marti, C. N., \& Jallo, N. (2013). Family cohesion, acculturation, maternal cortisol, and preterm birth in Mexican-American women. International Journal of Women's Health, 5, 243+. doi: 10.2147/IJWH.S42268

Schwartz, S. J., Unger, J. B., Zamboanga, B. L., and Szapocznik, J. (2010). Rethinking the concept of acculturation: Implications for theory and research. The American Psychologist, 65(4), 237-251. doi: http://dx. doi.org/10.1037/a0019330

Sitzman, K, \& Eichelberger, L. W. (2004). Understanding the work of nurse theorists: A creative beginning. Sudbury, MA: Jones and Bartlett Publishers.

Stinson, J. C., Lee, K. A., Heilemann, M. S., Gross, G., \& Koshar, J. H. (2000). Comparing factors related to low birth weight in rural Mexico-born and US-born Hispanic women in Northern California. Family and Community Health, 23(1), 29-40. Retrieved from http:// ovidsp.tx.ovid.com

Thornton, P. L, Kieffer, E. E., Salabarría-Peña, Y., OdomsYound, A., Willlis, S. K., . . .Salinas, M. A. (2006). Weight, diet, and physical activity-related beliefs and practices among pregnant and postpartum Latino women: The role of social support. Maternal and Child Health Journal, 10(1), 95-104. doi: 10.1007/s10995-0050025-3

Torres, L., \& Rollock, D. (2004). Acculturative distress among Hispanics: The role of acculturation, coping, and intercultural competence. Journal of Multicultural Counseling and Development, 32(3), 155-168. Retrieved from http://proquest.com

United States Census Bureau. Census 2010. Retrieved from http://www.census.gov/prod/cen2010/briefs/ c2010br-04.pdf
United States Census Bureau. (2013.) State and county quick facts: Michigan. Retrieved from http://quickfacts. census.gov/qfd/states/26/26139.html

Vatten, L. J., \& Skjaerven, R. (2003). Effects on pregnancy outcome of changing partners between first two births: Prospective population study. British Medical Journal (International Edition), 327(7424), 1138-1142. doi: 10.1136/bmj.327.7424.1138

Weigers, M. E. \& Sherraden, M. S. (2001). A critical examination of acculturation: The impact of health behaviors, social support and economic resources on birth weight among women of Mexican descent. The International Migration Review, 35(3), 804-839. doi: 10.1111/ j.1747-7379.2001.tb00042.x

Whitehead, N., Hill, A. A., Brogan D. J. \& Blackmore-Prince, C. (2002). Exploration of the threshold analysis in the relation between stressful life events and preterm delivery. American Journal of Epidemiolo$g y, 155(2), 117-124$. doi: 10.1093/aje/155.2.117

Yali, A. M., \& Lobel, M. (1999). Coping and distress in pregnancy: An investigation of medically high risk women. Journal of Psychosomatical Obstetrics and Gynecology, 20, 39-52.

Yang, Q., Greenland, S., \& Flanders, W. D. (2006). Associations of maternal age and parity related factors with trends in low-birth weight rates: United States, 1980 through 2000. American Journal of Public Health, 96(5), 856-861. doi: 10.2105/AJPH.2004.049312

Zambrana, R. E., Scrimshaw, S. C., Collins, N., \& Dunkel-Schetter, C. (1997). Prenatal health behaviors and psychosocial risk factors in pregnant women of Mexican origin: The role of acculturation. American Journal of Public Health, 87, 1022-1026. Retrieved from http:// www.ncbi.nlm.nih.gov 


\section{Acknowledgments}

To the men and women in resource poor countries who have shaped my understanding of how culture impacts health outcomes and have challenged me to work with them as partners and not patients.

\section{The Author}

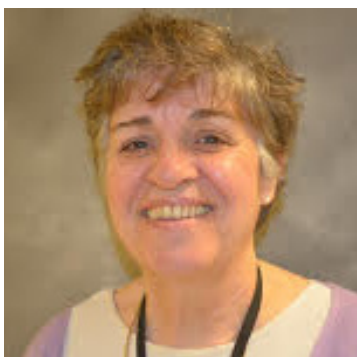

Paulette A. Chaponniere, PhD, MPH, RN.

Dr. Chaponniere has extensive experience in 20 Sub-Saharan African countries in women and children's health programs: assessment, implementation and evaluation. Her focus has been to build on what local communities do well and to carefully consider how culture impacts health outcomes. She has created health education materials which have been used worldwide, including stories, songs, and story boards. Currently, faculty member of nursing program at Grand Valley State University. 